\title{
Prospections aériennes
}

\section{Bernard Lambot}

\section{(2) OpenEdition \\ Journals}

Édition électronique

URL : http://journals.openedition.org/adlfi/11471

ISSN : 2114-0502

Éditeur

Ministère de la culture

Référence électronique

Bernard Lambot, «Prospections aériennes », ADLFI. Archéologie de la France - Informations [En ligne] Champagne-Ardenne, mis en ligne le 01 mars 2004, consulté le 02 mai 2019. URL : http://

journals.openedition.org/adlfi/11471

Ce document a été généré automatiquement le 2 mai 2019.

(c) Ministère de la Culture et de la Communication, CNRS 


\title{
Prospections aériennes
}

\author{
Bernard Lambot
}

Identifiant de l'opération archéologique : 4889

Date de l'opération : 2004 (PA)

1 L'année a été prolifique et les vols concentrés sur la fin du printemps et le début de l'été ont permis de photographier 220 sites: 117 dans la Marne, 59 dans les Ardennes et 51 dans l'Aube. Les conditions météorologiques moyennes, dans une région où les brumes sont souvent présentes même par grand soleil, n'ont pas permis de photographies de qualité exceptionnelle. Il n'en reste pas moins la découverte de quelques sites remarquables et l'apparition de sites connus sous de nouveaux aspects ou bien plus lisibles.

2 Les prospections dans le département des Ardennes ont permis de photographier de nouveau des sites connus pour presque la moitié des découvertes de cette année. En effet, au Nord de l'Aisne, les couvertures limoneuses des plateaux, l'épaisseur des alluvions en vallée puis l'épaisse forêt ne favorisent pas les découvertes sauf dans des conditions exceptionnelles. Toute la partie sud du département est prospectée depuis une trentaine d'années et la découverte d'un nouveau site est bien évidemment plus rare que dans des régions encore peu étudiées. L'apparition du site d'Hauviné «Les Heurteaux » (Fig. n ${ }^{\circ} 1$ : Le site d'Hauviné «Les Heurteaux» (Ardennnes)), d'une façon exceptionnelle, modifie totalement la vision que nous en avions depuis les quelques fouilles effectuées au XIXe $\mathrm{s}$. et les photos aériennes antérieures, qui n'en montraient ponctuellement que des fragments. Ce cliché, parmi d'autres, justifie à lui seul la poursuite des prospections.

Dans le département de la Marne, le nombre de découvertes correspond à une prospection intensive, dans une région particulièrement favorable par son sous-sol crayeux. Dans le secteur des Marais de Saint-Gond, les tourbières ont été un attrait pour les populations protohistoriques et les découvertes sont régulières, suivant les conditions atmosphériques. 
Dans l'Aube, seule la partie nord du département a été prospectée. Les découvertes sont pour la plupart des structures fossoyées funéraires. Certains sites couvrent plusieurs hectares et toutes les périodes sont représentées, des grands enclos doubles du Bronze aux enceintes quadrangulaires de la fin de l'indépendance gauloise et probablement du début de la période romaine. Un site spectaculaire associe plusieurs enclos quadrangulaires à structures centrales à Viapres (Fig. nº 2 : Enclos à Viapres (Aube)) . L'une de ces enceintes pourrait être un lieu cultuel, elle présente toutes les caractéristiques des sanctuaires tels qu'ils sont connus maintenant à l'époque gauloise. L'intensification des prospections dans ce département est envisagée dans les prochaines années.

\section{ANNEXES}

Fig. $\mathrm{n}^{\circ} 1$ : Le site d'Hauviné « Les Heurteaux » (Ardennnes)

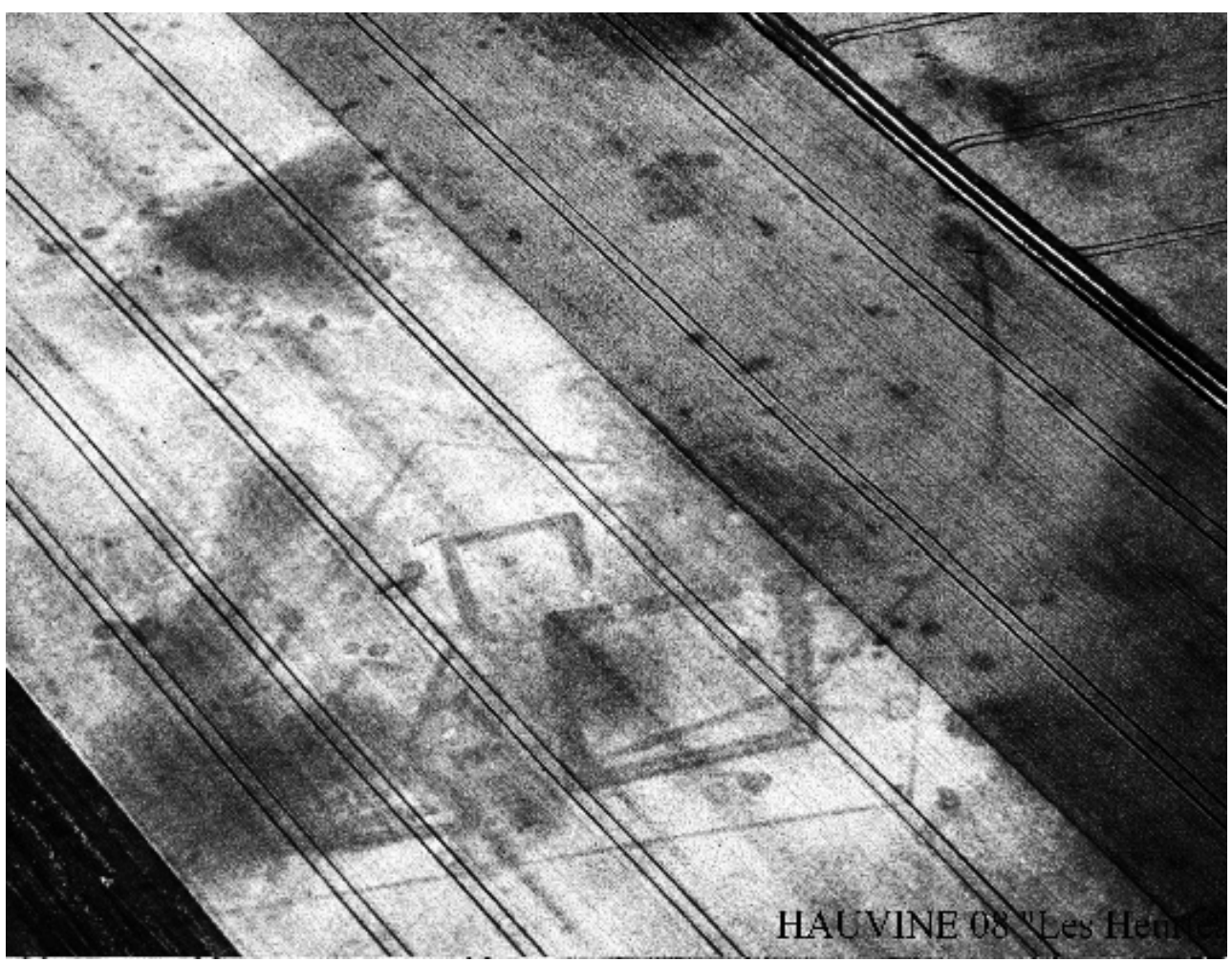

Auteur(s) : Lambot, Bernard (SRA). Crédits : Lambot, Bernard (2004) 
Fig. $n^{\circ} 2$ : Enclos à Viapres (Aube)

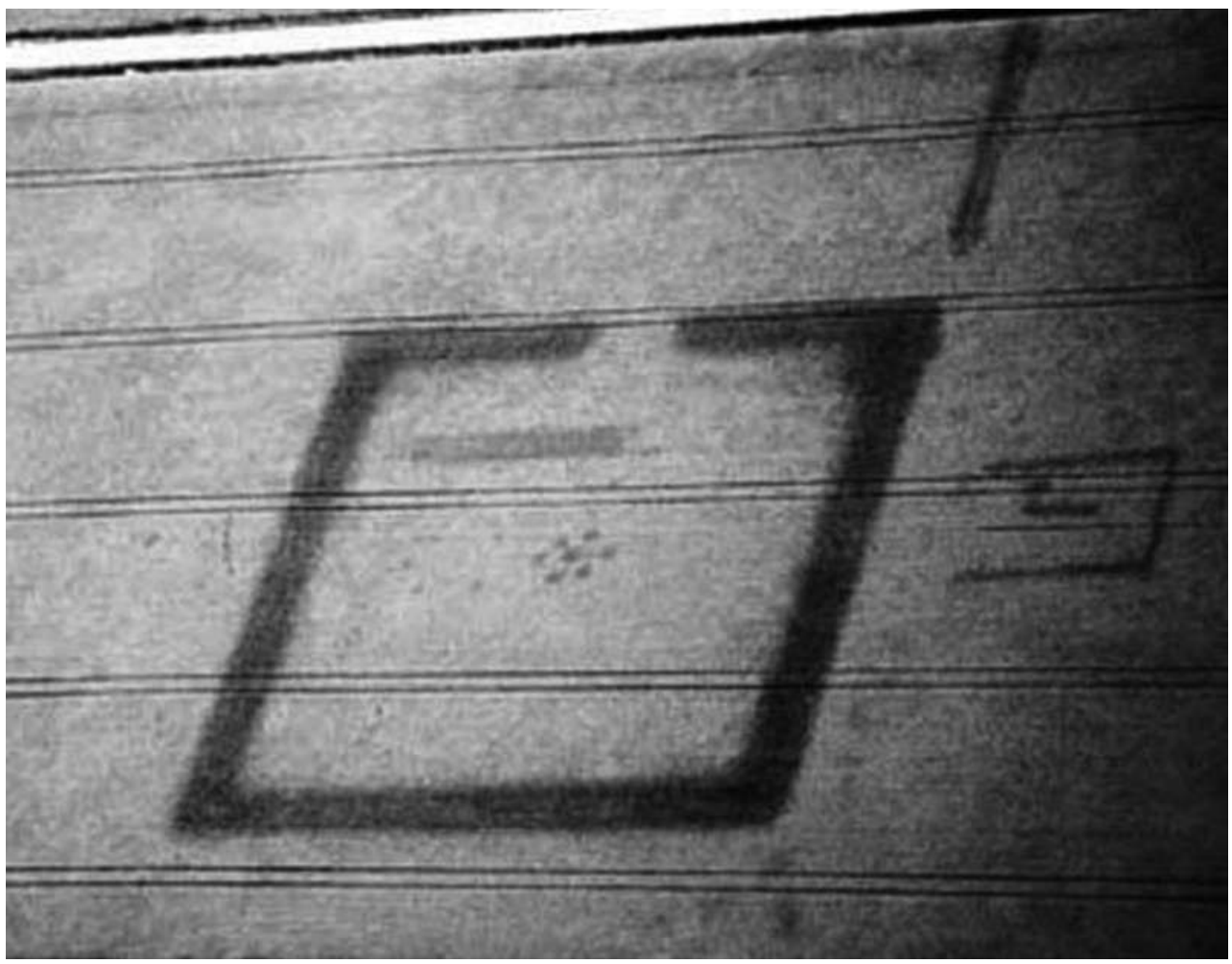

Auteur(s) : Lambot, Bernard (SRA). Crédits : Lambot, Bernard (2004)

INDEX

operation Prospection aérienne (PA)

Index chronologique : âge du Bronze, Empire romain, Protohistoire

Thèmes : enceinte, enclos, enclos quadrangulaire, photographie aérienne, sépulture, tourbière Index géographique : Champagne-Ardenne

\section{AUTEURS}

\section{BERNARD LAMBOT}

SRA 